governance can enhance sector investments, ${ }^{5}$ including economic growth, ${ }^{6}$ education, ${ }^{7}$ and health, ${ }^{8}$ and that it can be an important condition for achieving the SDGs. ${ }^{9}$

Some donors, such as the US Agency for International Development (USAID), have prioritized integrated programming, ${ }^{3}$ intentionally combining governance and sectoral investments in strategic collaboration to boost outcomes in specific contexts. ${ }^{10}$ Yet, integration at the programmatic level has often proven challenging in practice. ${ }^{11,12}$ Even when sectoral and governance investments are combined, limited empirical evidence exists on the results of integrated governance on service outcomes, hampering further adoption of integrated program designs.

This brief provides new evidence by interrogating what value an integrated governance approach adds to health service readiness and delivery using data from a quasi-experimental study in Senegal. The study contributes to an emerging body of research examining governance and sector program integration, including recent or active studies in Malawi, ${ }^{13}$ Democratic Republic of the Congo, ${ }^{14}$ and Guinea. ${ }^{15}$ We find that integrating governance and health programs can enhance access to and quality of health services, and we explore pathways that link good governance to these service readiness improvements. The remainder of this brief lays out the Senegalese context and research design, presents our findings, and draws implications for future integrated governance programs and research.

\section{The Case of Senegal}

Improving health outcomes (SDG 3) is a policy priority but remains a challenge for the Government of Senegal. ${ }^{16}$ SDG monitors have noted Senegal's moderate health improvements, but flag significant remaining issues. ${ }^{17}$ In the Senegalese health system, local health facilities range from village-level health huts to commune-level health posts and department-level health centers. ${ }^{18}$ Health huts deliver basic primary care and a minimum package of family planning, maternal, and child health services, supervised by health post staff. Service range and facility sophistication increase at posts and centers. ${ }^{19}$

In Senegal's decentralized governance structure, local governments (communes) play an important role in improving healthcare because they have been delegated overall management of the budget and specific government, regulatory, and service provision responsibilities. However, communal planning and budgeting for health services are often unresponsive to community needs. Facility budgets are frequently driven by funds earmarked by the central government and routinized budget management rather than by local priorities and the actual costs to provide needed services. ${ }^{20}$
Realizing this untapped potential for local governments to improve healthcare, USAID concurrently funded the Governance for Local Development (GoLD) [2016-2022] and the Integrated Services and Healthy Behavior Adoption (Neema) [2016-2021] programs and mandated they work together in targeted regions, with the assumption that the governance investment would add value to the health program outcomes.

Neema worked in seven regions to promote a communitybased approach to increasing access and use of quality health services (Figure 1). Activities included investing in health facilities and the health workforce and engaging Health Local Committees (comités de développement sanitaires; CDS) in facility monitoring and accountability. The CDS, made up of community members, elected officials, and facility staff, educates community members, promotes citizen participation, and monitors service quality and management.

GoLD collaborated with Neema in four regions (Figure 1) using an integrated approach to improve the capacity of local governments to provide priority services by strengthening skills and processes for planning, budgeting, community involvement, and resource mobilization (Figure 2). In line with the recognized need for a multilevel approach to improving service delivery, ${ }^{21-23}$ GoLD supports Municipal Councils and their technical working groups, such as Health Technical Commissions $\left(\mathrm{HTC}^{*}\right)$, charged with defining and monitoring

\section{Figure 1. Activity regions for Neema + GoLD and Neema only}

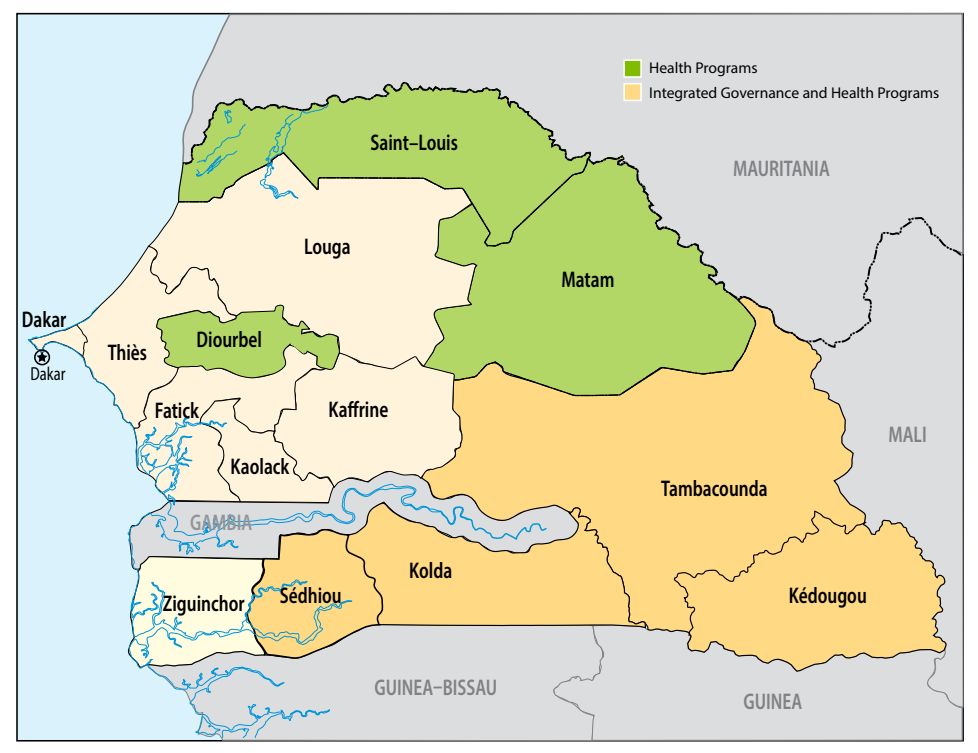

Source: Adapted from NordNordWest - Own work, using United States National Imagery and Mapping Agency data, World Data Base II data, Agence Nationale de la Statistique et de la Démographie Sénégal. Creative Commons BY-SA 3.0 
local health policy, as well as CDS. The regions in which Neema is active without GoLD form the control group for our study of the integrated governance treatment (Neema + GoLD).

Figure 2 shows the specific Neema-only (control) and Neema and GoLD (treatment) interventions at mayor and municipal council, HTC, CDS, and facility levels. The smaller, shaded boxes show interventions that Neema implemented in all communes. The larger horizontal bars show interventions that Neema and GoLD coordinate to implement in treatment communes. Thus, the horizontal bars, including boxes, represent the entirety of integrated interventions in treatment communes; the boxes represent health-sector activities occurring in control communes. Figure 2 underscores the substantial additional integrated activities at the municipal and HTC levels in treatment communes.

In French, HTCs are commissions techniques de santé; to reduce confusion over similar acronyms, we use the English-based acronym HTC for health technical commissions and French-based CDS for health local committees.

\section{Research Design}

This research seeks to determine what value the integrated governance approach adds, compared with the health interventions alone, operationalized as three research questions focused on health service readiness and delivery:

1. Does an integrated governance approach improve the level and/or sources of funding available for commune-level health services?

2. Does an integrated governance approach improve commune-level health governance functions?

3. Does an integrated governance approach improve health service delivery?

We took a quasi-experimental approach to assess the effect of integrated governance treatment in the 50 communes where Neema and GoLD worked together-compared with 60 statistically matched control communes within the same regions that received the health program alone (Neema only) on health service delivery.

\section{Figure 2. Summary of Neema (health-only/control) and Neema + GoLD (integrated/treatment) interventions}

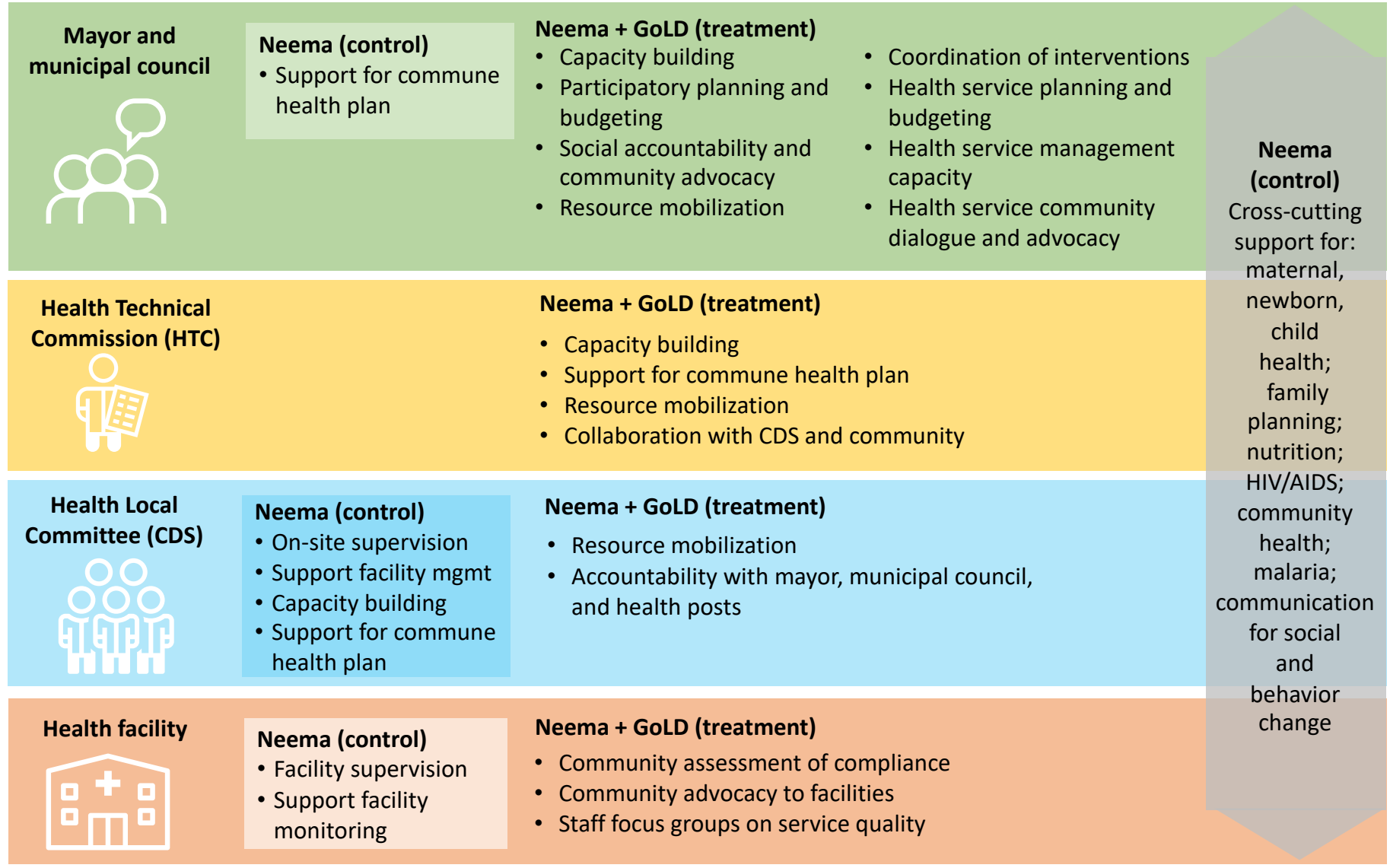


First, to select our study communes, we calculated propensity scores for all available communes (50 treatment and 98 possible control communes within the four regions) based on 13 covariates, ${ }^{\dagger}$ then matched treatment and control communes based on overlapping propensity scores and data collected in the selected 110 communes. Second, after data collection, we applied a 1:1 Mahalanobis optimal matching procedure, which balances covariates exactly, to ensure similar baseline values among matched communes, increasing precision and power. This two-step matching allowed us to isolate the added value of integrated programming within the parameters of ongoing implementation by removing bias and comparing as similar locations as possible among treatment and control communes.

Working with a Senegalese field research team, we surveyed 659 respondents (110 municipal councilors, 110 HTC councilors, 229 CDS members, 83 health hut staff, 101 health post staff, 26 health center staff) in 110 selected communes in the Kédougou, Kolda, Tambacounda, and Sédhiou regions. The surveys, primarily made up of closed-ended questions, were conducted in March 2020.

The survey collected data on health service readiness and delivery dimensions:

- Health resources: reports of health service funding levels, sources, and changes. No secondary financial data were available for triangulation.

- Functionality of health governance bodies: whether HTCs and CDSs were established, performing expected functions, identifying service delivery issues, and addressing identified issues. Questions were developed based on the GoLD program approach and European Centre for Development Policy Management Capability Framework. ${ }^{24}$

- Health service delivery: short-term service delivery dimensions for availability, access, use, and quality at health facilities (note that this research does not gauge patient outcomes such as mortality and morbidity). Drawing on health service frameworks from the World Health Organization and the US Department of Health and Human Services, and input from health experts, we define service delivery dimensions as follows (Table 1). Availability gauges provision of health services and staff. Access relates to patients' ability to take advantage of available health facility resources. Use indicates patients' actual utilization of services. Quality is measured by staff competencies,

\footnotetext{
$\dagger$ The covariates considered in the propensity score model were population density; number of live births a year; child mortality; exclusive breastfeeding rate, HIV prevalence, under-five diarrhea prevalence, DPT vaccination rate, education attainment for males and females, electricity use (as measured by "night lights" data); agricultural density (land use); vegetation index (land use); and distance from major city (travel time measure).
}

\begin{tabular}{l} 
Table 1. Health service readiness and delivery dimensions \\
and subtopics covered in survey \\
\begin{tabular}{l|l}
\hline Dimensions & Subtopics \\
\hline Availability & - Number of employees \\
& - Services provided \\
\hline Access & - Weekly hours of operation and employee hours \\
& - Services offered in last month \\
& - Stockout of relevant medications \\
- Number of health insurance patients & - Referrals made to another facility \\
\hline Use & - Total patients seen in one month \\
& - Patients seen for specific services in one month \\
& perceived and actual year-over-year change in \\
- Perceived year-over-year change in number of & medically assisted births \\
\hline Quality & - Specific technical personnel \\
- Infrastructure and personnel investment over last year \\
- Availability of patient registers \\
- Proper disposing of human waste and sharps \\
- Availability and functionality of electricity, running \\
water, and toilets
\end{tabular} \\
\hline
\end{tabular}

compliance with professional norms, and available infrastructure. ${ }^{25,26}$ Survey questions corresponding to each dimension were drawn from the 2017 Senegal Demographic Health Survey. 27

The reported results reflect multivariate statistical analysis of our survey data with separate logistic regressions for different health facility levels (health huts and health posts; regressions do not include health center data due to the small number surveyed) and different health governance bodies (HTCs and CDS). ${ }^{\ddagger}$ For brevity and clarity, we represent statistically significant results as predicted probabilities, calculated from regression coefficients. Predicted probabilities express the likelihood of a certain outcome occurring. Across these analyses, we only report statistically significant findings. ${ }^{\S}$

¥ We considered pooling analysis across health facilities to increase sample size but opted to separate regressions by facility for two reasons. First, service offerings vary by facility type; survey responses could thus not be considered comparable (and aggregable) across huts, posts, and centers. Second, because our unit of analysis is the commune, there were methodological complications to both aggregating responses-when there was more than one health hut or post in a commune-and appropriately weighting health centers that spanned more than one commune.

$\$$ Regressions included treatment variable and standard control variables (agricultural land density, female education, HIV prevalence, under-five diarrheal prevalence, population), using logistic regression and least squares regression to fit general linear models. Control variables were statistically significant in some models but are not reported here as they do not affect interpretation of the main variables of interest. Results available upon request. 


\section{Does Integrated Governance Enhance Health Service Readiness and Delivery?}

Our analysis shows that integrated governance is associated with improvements in some health service readiness and delivery dimensions in Senegal. Specifically, we found statistically significant evidence of improvements in some aspects of access and quality at health facilities in treatment communes compared with control communes in the areas below. There were statistically significant differences in only a subset of variables gauged in the survey. However, taken together, they indicate a higher level of general service readiness in treatment communes. ${ }^{26}$

\section{Access}

Health huts in treatment communes are more likely to be open (accessible) than health huts in control communes. On average, the predicted probability (likelihood) of a health hut in treatment communes being open 7 days a week is 82 percent, compared with 53 percent for control communes (see Figure 3).

\section{Figure 3. Predicted probabilities for health service delivery variables by treatment/control communes (using average values for standard controls)}

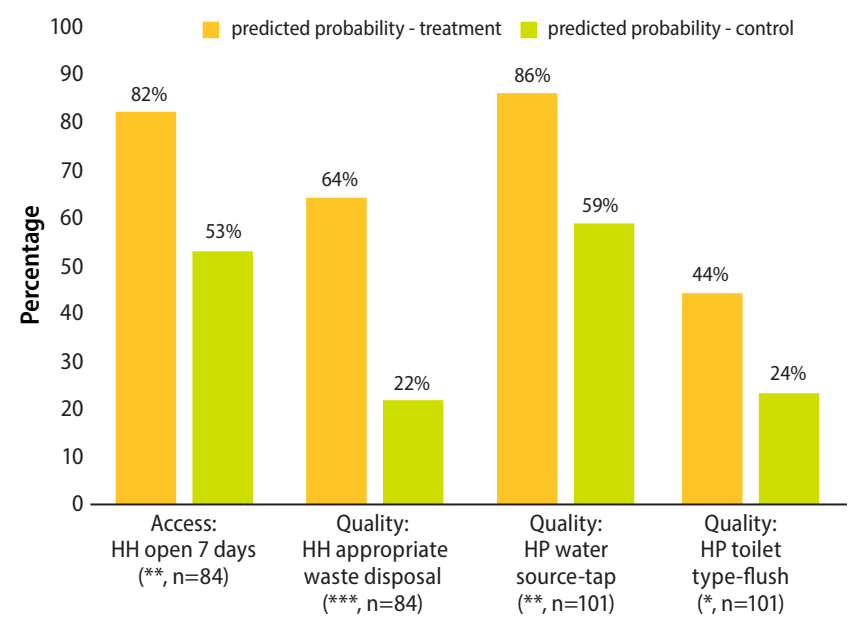

Notes: $\mathrm{HH}=$ health huts; $\mathrm{HP}=$ health posts. Asterisks indicate levels of statistical significance for treatment variable coefficient in regressions using dependent variables on $\mathrm{x}$-axis.

${ }^{*} p<0.1{ }^{* *} p<0.05 * * * p<0.001$

Quality

Compared with control communes, health huts in treatment communes have more community health officers on staff (an average of 1.2 community health officers vs. 1 in control commune health huts; regression coefficient significant at $p<.1$ level.). This means that treatment health huts more frequently had more trained, qualified staff members. Treatment commune huts are also more likely to dispose of waste correctly (64 percent predicted probability compared with 22 percent for control, Figure 3). Health posts in treatment communes are more likely to have higher quality infrastructure (tap water and flush toilets) than those in control communes. Treatment health posts have an 86 percent predicted probability of having higher quality tap water source and a 44 percent predicted probability of having the higher quality flush toilets (Figure 3).

The study did not find statistically significant differences in availability or use of Health Hut or Health Post services in treatment and control communes, nor in access to Health Post services.

\section{How Does Integrated Governance Add Value to Health Service Delivery?}

The study also suggested some possible mechanisms for how integrated governance might contribute to better health service delivery.

Treatment communes have better functioning HTCs that are more actively addressing health service problems. HTCs in treatment communes more often self-report providing advice to the Municipal Council (predicted probability 71 percent for HTCs in treatment communes, compared with 54 percent for controls; Figure 4) and addressing health service delivery issues in their commune ${ }^{* *}$ (predicted probability 85 percent

\section{Figure 4. Predicted probabilities for HTC and CDS functionality by treatment/control communes (using average values for standard controls)}

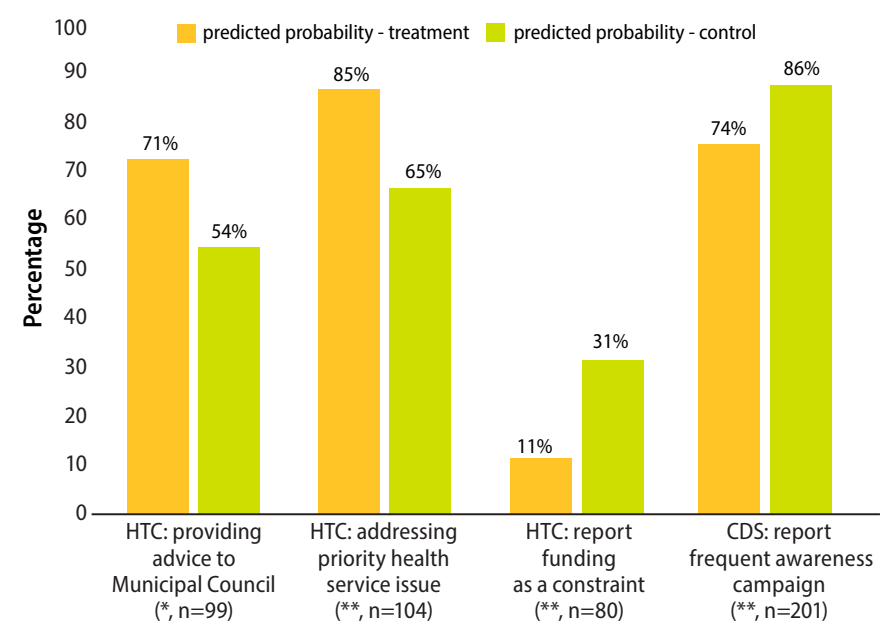

Note: Asterisks indicate levels of statistical significance for treatment variable coefficient in regressions using dependent variables on $\mathrm{x}$-axis.

${ }^{*} p<0.1{ }^{* *} p<0.05$ *** $p<0.001$

\footnotetext{
** HTC councilors were asked if they had identified a health service issue in the community, made a plan, and made progress in addressing the issue. The issues most frequently reported in treatment communes were service availability, access, and resources.
} 
in treatment communes, compared with 65 percent for controls). These results suggest that HTCs exposed to integrated governance interventions are more actively working to improve health service delivery by engaging municipal decisionmakers and taking direct action to resolve problems. Furthermore, HTCs in treatment communes are less likely to report funding constraints (predicted probability 11 percent in treatment communes, compared with 31 percent for controls).

There was only one statistically significant difference in CDS performance between treatment and control communes. A higher percentage of control commune CDSs report conducting an awareness campaign in the last year (predicted probability 74 percent in treatment communes, 86 percent in control).

\section{Implications for Health Care in Senegal, Program Design, and Achieving the SDGs}

The study findings demonstrate that an integrated governance approach-combining health sector expertise with support for governance structures at community, facility, and municipal levels-has a positive association with some indicators important in health service readiness and delivery. Statistically significant evidence of improvements in several measures of access and quality dimensions at health facilities in treatment communes indicate a higher level of service readiness. ${ }^{\dagger \dagger}$ These measures-showing that health facilities are open more, with higher quality infrastructure and staff more likely to follow correct procedures after integrated governance treatment-could illuminate one link in the causal chain for delivering high quality health services. While separate health programs and governance programs can independently achieve results, these findings imply that integration amplifies sectoral outcomes. Although the study did not test governance interventions alone, prior research suggests it is unlikely a stand-alone governance program would have delivered similar results. ${ }^{28}$

\section{Stronger Health Governance Structures and Social Accountability}

The findings regarding stronger HTCs in treatment communes demonstrate that strengthening local government capacity and supporting social accountability are particularly important elements of an integrated governance approach. We posit that these two elements could explain the added value of integrating governance and health programming.

\footnotetext{
$\dagger^{\dagger}$ World Health Organization defines readiness as "the cumulative ability of components required to provide services. It comprises tracer items for the following major domains: infrastructure/amenities, basic supplies/ equipment..., standard precautions, laboratory tests, medicines and commodities."4, p. 11
}

An integrated approach to these interventions may overcome a critical bottleneck between citizens and local government. Social accountability efforts to improve service delivery often fail due to lack of response from higher level decisionmakers. ${ }^{23,29}$ For example, a series of seminal studies have focused on the effects of community monitoring on service delivery in Uganda. ${ }^{21,30,31}$ The most recent research, analyzing effects of years-long support to community advocates, shows that such efforts in Uganda led to notable changes in accountability relations. However, in only eight of 18 districts did officials fulfill or exceed stated commitments to improve health services. ${ }^{21}$

Notably, HTCs in Senegal were significantly more likely not only to have identified health service delivery issues but also to report using municipal resources to improve services in the integrated governance treatment communes in our study. These results suggest that, by complementing social accountability at the facility level with capacity-building and resource mobilization for commune-level governance bodies, the integrated governance approach increased local government responsiveness to deliver concrete improvements in health services. Further research might explore whether and how these health facility readiness improvements were spurred by new or enhanced collaborative processes, perceived value by citizens or government in taking direct action to address identified problems, and/or clarified roles and enhanced capacity for health service planning, delivery, and monitoring that could signal a persistent shift in systemic, collaborative accountability efforts. ${ }^{22}$

Despite these encouraging results, it is important to emphasize that-like many others ${ }^{32,33}$ - the study links integrated governance interventions with improvements in services and facility-level processes and readiness. More research is needed to make the link between governance interventions and actual patient outcomes, such as mortality and morbidity.

\section{Implications for Health Services in Senegal}

The findings suggest that achieving quality, universal health care is not only a health-sector issue but requires a more integrated approach. Specifically, the findings suggest that strengthening the capacity and involvement of municipal administration and health governance bodies adds value to more technocratic support to health facilities. In Senegal, national, regional, and local government agencies responsible for health service delivery could benefit from taking an integrated approach to improving health service delivery that attends to health facilities, health governance, and the wider governance system. Further research will deepen our understanding of the effects of integrated programming. 


\section{Implications for International Development Program Design}

If integrated programming can add value, then program designers and funders need to pay attention to cofunding, colocation, and concurrent timelines. Support for collaborative work planning, activity design, implementation, and shared learning would support integrated programming. In congruent locations and time frames, sector-specific programs and governance strengthening program can bring their tools and expertise. When collaboration is intentional, well-resourced, and encouraged by stakeholders at multiple levels, enhanced multisector outcomes could be realized if intersectoral barriers, including siloed funding and pressures for sectoral indicator performance, could be addressed. Additional research in different contexts, including replicating a similar research design in other sectors, would further illuminate the patterns reported here.

For the global community to continue and accelerate progress to its collective SDGs, this research underscores the value of investments in integrated governance and encouraging coordinated programmatic investment. Simultaneously strengthening both direct service delivery and the wider governance system can achieve greater advancements in sustainable development than either alone.

\section{References}

1. United States Agency for International Development (USAID). US foreign aid explorer. Washington (DC): USAID; 2021 [cited 2021 March 24]. Available from: https://foreignassistance.gov/aid-trends

2. World Bank. World development report 2017: governance and the law. Washington (DC): World Bank; 2017. https://doi.org/10.1596/978-1-46480950-7

3. USAID. USAID strategy on democracy human rights and governance; 2013. https://www.usaid.gov/sites/default/files/documents/1866/USAIDDRG_fina-_6-24-31.pdf

4. Kaufmann D, Kraay A, Mastruzzi M. Governance matters VIII: aggregate and individual governance indicators, 1996-2008 World Bank Policy Research Working Paper 4978. Washington (DC): World Bank; 2009 Jun 29. https://doi.org/10.1596/1813-9450-4978

5. Brinkerhoff DW. Democratic governance and sectoral policy reform: tracing linkages and exploring synergies. World Dev 2000;28(4):601-15. https://doi.org/10.1016/S0305-750X(99)00147-3

6. Acemoglu D, Naidu S, Restrepo P, Robinson JA. Democracy does cause growth. Cambridge (MA): National Bureau of Economic Research; 2014. https://doi.org/10.3386/w20004

7. Dahlum S, Knutsen CH. Do democracies provide better education? Revisiting the democracy-human capital link. World Dev 2017;94:186-99. https://doi.org/10.1016/j.worlddev.2017.01.001

8. Wang Yt, Mechkova V, Andersson F. Does democracy or good governance enhance health? New empirical evidence 1900-2012. Polit Res Q 2018;72(3):554-59. https://doi.org/10.1177/1065912918798506
9. Organisation for Economic Co-operation and Development (OECD). Sustainable development goals and public governance. Paris: OECD; n.d. [cited 2021 Jul 13]; Available from: https://www.oecd.org/gov/sustainabledevelopment-goals-and-public-governance.htm

10. Brinkerhoff DW, Wetterberg A. Governance and sector outcomes: making the connections. RTI Press Publication PB-0019-1809. RTI Press; 2018. https://doi.org/10.3768/rtipress.2018.pb.0019.1809

11. Falisse JB, Ntakarutimana L. When information is not power: communityelected health facility committees and health facility performance indicators. Soc Sci Med 2020;265:113331. https://doi.org/10.1016/j. socscimed.2020.113331

12. Francetic I, Fink G, Tediosi F. Impact of social accountability monitoring on health facility performance: evidence from Tanzania. Health Econ 2021;30(4):766-85. https://doi.org/10.1002/hec.4219

13. Hodel L, Dasgupta B. Malawi CDCS integrated development impact evaluation endline report. Washington (DC): USAID; 2019. Available from: https://pdf.usaid.gov/pdf_docs/PA00TNP3.pdf

14. Comacho L, Dionne K, Rojas-Arellano I. Impact evaluation of USAID/ DRC integrated governance activity midline report. Washington (DC): USAID; 2020. Available from: https://pdf.usaid.gov/pdf_docs/ PA00WQSW.pdf

15. USAID. Strengthening civil society: Guinea. Citizens' involvement in health governance. Washington (DC): USAID; 2020. Available from: https://pdf.usaid.gov/pdf_docs/PA00X3CT.pdf

16. Ministère de la Santé et de l'Action Sociale. Stratégie Nationale de Santé Digitale 2018-2023. Republique du Sénégal; 2018. Available from: http:// www.sante.gouv.sn/sites/default/files/plsantedigitale.pdf

17. Sustainable Development Solutions Network. Sustainable development report 2019: appendix 1. Country profiles. Sustainable Development Solutions Network; 2019. Available from: https://sdsna.github. io/2019AfricaIndex/2019_africa_index_country_profiles.pdf

18. The Primary Health Care Performance Initiative. Senegal. 2019. Available from: https://improvingphc.org/senegal

19. Devlin K, Pandit-Rajani T, Egan KF. Senegal's community-based health system model: structures, strategies, and learning. Arlington (VA): Advancing Partners \& Communities; 2019.

20. Gilbert G, Taugourdeau E. The local government financing system in Senegal. In: Dafflon B, Madies T, editors. The political economy of decentralization in Sub-Saharan Africa. Washington (DC): Agence Française de Développement and World Bank; 2013. pp. 207-64.

21. Bailey A, Mujune V. Bottom-up accountability in Uganda: learning from people-centered, multi-level health advocacy campaigns. Working Paper. Accountability Research Center; 2021 Feb. Available from: https:// accountabilityresearch.org/wp-content/uploads/2021/02/ARC-Workingpaper-8-Uganda-health-advocacyWEB-02-22-2021.pdf

22. Halloran B. Accountability ecosystems: The evolution of a keyword. Accountability Research Center; 2021 Mar 29 [cited 2021 Jul 10]. Available from: https://accountabilityresearch.org/accountability-ecosystems-theevolution-of-a-keyword/

23. Wetterberg A, Brinkerhoff DW, Hertz JC, editors. Governance and service delivery: practical applications of social accountability across sectors. RTI Press Publication BK-0019-1609. Research Triangle Park (NC): RTI Press; 2016. https://doi.org/10.3768/rtipress.2016.bk.0019.1609 
24. Keijzer N, Spierings E, Phlix G, Fowler A. Bringing the invisible into perspective: reference paper for using the $5 \mathrm{Cs}$ framework to plan, monitor and evaluate capacity and results of capacity development processes. Maastrich: ECDPM; 2011. Available from: https://ecdpm. org/publications/5cs-framework-plan-monitor-evaluate-capacitydevelopment-processes/

25. US Department of Health and Human Services. 2015 national healthcare quality and disparities report and 5th anniversary update on the national quality strategy. AHRQ Publication 16-0015. Rockville (MD): Agency for Healthcare Quality and Research; 2016. Available from: https://archive. ahrq.gov/research/findings/nhqrdr/nhqdr15/index.html

26. World Health Organization (WHO). Monitoring the building blocks of health systems: a handbook of indicators and their measurement strategies. Geneva: WHO; 2010.

27. Agence National de la Statistique et de la Demographié. Senegal: Enquête Continue sur la Prestation des Services de Soins de Santé (ECPss). 2018. Available from: https://www.dhsprogram.com/pubs/pdf/SPA27/SPA27.pdf

28. Ciccone DK, Vian T, Maurer L, Bradley EH. Linking governance mechanisms to health outcomes: a review of the literature in low- and middle-income countries. Soc Sci Med 2014;117:86-95. https://doi. org/10.1016/j.socscimed.2014.07.010

29. Arkedis J, Creighton J, Dixit A, Fung A, Kosack S, Levy D et al. Can transparency and accountability programs improve health? Experimental evidence from Indonesia and Tanzania. World Dev 2021;142:105369. https://doi.org/10.1016/j.worlddev.2020.105369

30. Björkman M, Svensson J. Power to the people: evidence from a randomized field experiment on community-based monitoring in Uganda. Q J Econ 2009;124(2):735-69. https://doi.org/10.1162/qjec.2009.124.2.735

31. Bjorkman Nyqvist M, De Walque D, Svensson J. Information is power: experimental evidence on the long-run impact of community based monitoring. World Bank Policy Research Working Paper 7015. Washington (DC): World Bank; 2014. Available from: https://openknowledge. worldbank.org/handle/10986/20364

32. Mant J. Process versus outcome indicators in the assessment of quality of health care. Int J Qual Health Care 2001;13(6):475-80. https://doi. org/10.1093/intqhe/13.6.475

33. Dunsch FA, Evans DK, Eze-Ajoku E, Macis M. Management, supervision, and health care: a field experiment. Cambridge (MA): National Bureau of Economic Research; 2017. https://doi.org/10.3386/w23749

\begin{abstract}
About the Authors
Sarah Frazer, MA, is an evaluation and learning specialist and a gender equity and inclusion lead in RTI International's International Development Group. sfrazer@rti.org
\end{abstract}

Anna Wetterberg, PhD, is a senior social scientist in RTI's International Development Group and works as the senior manager of RTI Press. awetterberg@rti.org

Eric M. Johnson, PhD, is the Senior Director of Technical Leadership for RTI's International Development Group. ericjohnson@rti.org

\section{RTI Press Associate Editor}

Rebecca Flueckiger

\section{Acknowledgments}

While the results and interpretation presented here are entirely our own, we could not have conducted this study without input, support, and feedback from many others. We are grateful to Governance for Local Development (GoLD) colleagues_-particularly Jean-Michel Dufils, Fatoumata Sane, Mamadou Amadou Diako, Mamadou Lamarana Barry, Devang Pandya, Kara Reeve, and Moussa Faye - who supported this research throughout, while also allowing us to carry it out independently. USAID/Senegal funded the study, and Danny Dedeyan, Laura Campbell, Samba Ba and Samba Barry helped with the research design. Awa Taye Sarr expertly organized and led the survey data collection and, with Moustaphe Niang, made sure the data were presented and interpreted accurately. We also appreciated the engagement of IntraHealth colleagues Melanie Joiner, Sujata Bijou, El Hadji Yankhoba Dial, and Babacar Gueye, particularly with helping us understand the Neema project implementation and facilitating data collection. MSI staff Souleymane Barry, Lisa Slifer-Mbacke, and Sadio Coulibaly shared their own research with us. David Dow from Duke University's DevLab provided helpful review and comments on the research design. We are grateful to Derick Brinkerhoff, Lisa McGregor, and Alyson Lipsky for comments on an earlier draft and appreciate helpful comments from the anonymous reviewers. Finally, we want to especially acknowledge Stirling Cummings, assisted by Grant Swigart, whose statistical expertise enabled the quasi-experimental design and ensured the rigor of the results. This research was made possible with the generous support of the American people through the US Agency for International Development, in partnership with the RTI-implemented GoLD Program. The research team conducted the study independently and views represented are the authors' own.

Cover photo: KOLDA - SENEGAL: Souboune Mballo, 45 and mother of 5 poses for a group photo with her family at Diouta Dara village on February 10, 2019. Photo by Xaume Olleros for RTI International. www.flickr.com

RTI Press Research Briefs and Policy Briefs are scholarly essays on policy, methods, or other topics relevant to RTI areas of research or technical focus.

RTI International, 3040 East Cornwallis Road, PO Box 12194 Research Triangle Park, NC 27709-2194 USA

+1.919.541.6000ｒtipress@rti.org_www.rti.org

(02021 RTI International. RTI International is a trade name of Research Triangle Institute. RTI and the RTI logo are U.S. registered trademarks of Research Triangle Institute.

(c) (1) (-) This work is distributed under the terms of a Creative Commons (C) Attribution-NonCommercial-NoDerivatives 4.0 license (CC BYNC-ND), a copy of which is available at https://creativecommons.org/licenses/ by-nc-nd/4.0/legalcode 